\title{
REFLEXÕes SOBRE DIAGNÓSTICO PSIQUIÁTRICO À LUZ DA PSICOLOGIA ANALÍTICA
}

\author{
Fabiana Pinto de Almeida Bizarria
}

Mestre em Administração, Especialista em Saúde Pública, Psicóloga. Universidade de Fortaleza.

\section{Mônica Mota Tassigny}

Doutora em Educação. Professora do Programa de Pós-Graduação em Administração, Universidade de Fortaleza.

\section{Nara Thaís Guimarães Oliveira}

Mestranda em Psicologia, Psicóloga. Universidade Federal do Ceará

\section{Sabrina Leite Cardoso dos Santos Jesuíno}

Mestre em Psicologia, Especialista em Psicologia e Práticas de Saúde, Psicóloga. Universidade Federal do Ceará.

\begin{abstract}
Resumo
Ao adentrar no estudo da Psicopatologia, busca-se neste artigo abordar diferentes concepções sobre a loucura. Além disso, procura-se compreender algumas possíveis origens das perturbações psíquicas, bem como certas descrições das funções psicológicas em seu estado dito alterado. Descreve-se, de modo geral, as especificidades das diversas abordagens existentes em Psicopatologia e, de modo específico, o enfoque dado pela psicologia junguiana. Dessa forma, o estudo realiza a análise da história clínica de uma paciente internada em hospital psiquiátrico, tendo como foco os motivos da internação, os sintomas apresentados e o diagnóstico psiquiátrico definido, segundo classificação do CID-10. Além disso, tenta-se traçar um possível caminho que a Psicologia Analítica daria para a análise do caso. Desse modo, busca-se uma análise psicológica, não mais psiquiátrica, do sujeito em questão, atentando para a singularidade do seu sofrimento psíquico.
\end{abstract}

Palavras-chave: psicopatologia; diagnóstico psiquiátrico; funções psicológicas.

\section{REFLECTIONS ON THE LIGHT OF PSYCHIATRIC DIAGNOSIS ANALYTICAL PSYCHOLOGY}

\begin{abstract}
By entering the study of psychopathology, this article seeks to address various conceptions of madness. In addition, we seek to understand some possible origins of mental disorders, as well as descriptions of certain psychological functions in your state said changed. It describes, in general, the specificities of the different existing approaches in psychopathology and, specifically, the approach taken by Jungian psychology. Thus, the study performs a detailed clinical history of a patient's psychiatric hospital, focusing on the reasons for hospitalization, associated symptoms and psychiatric diagnosis defined according to the ICD-10 classification. Furthermore, attempts to trace a possible path that would Analytical Psychology for the analysis of the case. Thus, we seek a psychological analysis, no more psychiatric, the subject in question, noting the uniqueness of their psychological distress.

Keywords: psychopathology; psychiatric diagnosis; psychological functions.
\end{abstract}




\title{
REFLEXIONES SOBRE EL DIAGNÓSTICO PSIQUIÁTRICO DE LA LUZ DE LA PSICOLOGÍA ANALÍTICA
}

\begin{abstract}
Resumen
Al participar en el estudio de la psicopatología, este artículo trata de abordar diversas concepciones de la locura. Además, tratamos de entender algunos posibles orígenes de los trastornos mentales, así como la designación de determinados funciones psicológicas de su estado dicho cambiado. En él se describe, en general, las especificidades de los diferentes enfoques existentes en la psicopatología y, en concreto, el enfoque adoptado por la psicología junguiana. Así, el estudio realiza una detallada historia clínica del hospital de un paciente psiquiátrico, se centra en las causas de la hospitalización, los síntomas asociados y el diagnóstico psiquiátrico definido según la CIE-10 de clasificación. Por otra parte, los intentos de trazar un posible camino que la Psicología Analítica para el análisis del caso. Por lo tanto, buscamos un análisis psicológico, no más psiquiátrica, el tema de que se trate, teniendo en cuenta la singularidad de su angustia psicológica.

Palabras clave: diagnóstico psiquiátrico; psicopatología; funciones psicológicas.
\end{abstract}

\section{INTRODUÇÃO}

Antes de adentrarmos no foco da discussão, trataremos, em linhas gerais, sobre o percurso traçado por Jung na elaboração de sua teoria, bem como sobre alguns conceitos centrais para a compreensão da mesma. Jung nasceu em 1875, em Kesswil, Suiça. Em 1895, entrou no curso de medicina da Universidade de Basiléia. Em 1900, especializou-se em psiquiatria e iniciou seu trabalho na clínica psiquiátrica, no hospital Burghölzli, em Zurique, como assistente de Bleuler (Silveira, 1981).

O problema que ocupava o primeiro plano o interesse de pesquisa desse autor era o seguinte: o que se passa no espírito do doente mental? (Jung, 2006). Do ponto de vista clínico, os médicos não se ocupavam com o doente mental enquanto ser humano, enquanto individualidade, restringindo-se a um diagnóstico psiquiátrico, com base na descrição de sintomas e dados estatísticos. Sob esse aspecto, uma vez com o diagnóstico pronto, o caso era encerrado e, dessa forma, a psicologia do doente mental não desempenhava pepel algum. (Jung, 2006).

Sobre isso, Jung (2006) destacava a importância das contribuições de Freud para as pesquisas que desenvolveu posteriormente. Nesta situação, Freud foi essencial, principalmente devido às suas pesquisas fundamentais sobre a psicologia da histeria e do sonho. Assim, Jung (2006) fazia referência a Freud por ter introduzido a questão psicológica na psiquiatria. 
Em 1901, orientado por Bleuler, Jung começou a pesquisar, em sua tese de doutorado sobre a cisão de idéias na esquizofrenia e o fez através de experiências de associação, através das quais se podia penetrar na psicologia dos doentes (Jung, 2006). Por meio dessas experiências de associação verbal, Jung pretendia trazer esclarecimentos sobre a estrutura psicológica da esquizofrenia. Tais experiências transformaram-se em um método de exploração do inconsciente e conduziram Jung à descoberta dos complexos afetivos, o que se tratou da primeira contribuição do autor para a psicologia moderna. (Silveira, 1981).

Em seus estudos "A psicologia da demência precoce" (1907) e "O conteúdo das psicoses" (1908), Jung mostrou que, mesmo em distúrbios mais graves, é possível decifrar o sentido de sintomas de aparência desconexa, neles encontrando elos causais. Além disso, era preciso tomar em consideração certos fenômenos inegáveis que, entretanto, escapavam ao determinismo, como a coincidência de estados psíquicos e de acontecimentos físicos sem relações causais entre si, tais como sonhos, visões, premonições, por exemplo (Silveira, 1981).

\section{REFERENCIAL TEÓRICO}

Entende-se que um conceito é um nome descritivo, um termo geral aplicado a um grupo de fatos, sendo tanto mais útil quanto mais amplamente puder ser utilizado. Em sua teoria, Jung se utilizava de conceitos que têm um escopo muito vasto e, conseqüentemente, a explicação de tais conceitos é bastante limitada se comparada com a vastidão de aplicações e ramificações que podem ter. 0 próprio autor dizia propositalmente procurar se expressar por uma linguagem com duplo sentido, visto que esse duplo aspecto corresponde à natureza da psique, sendo, portanto, preferível a uma expressão de sentido único (Jung, 1962 apud Jung, 1985). Por outro lado, Jung dedicava-se a definir com precisão os termos por ele empregados.

Recomendava, porém, cautela com o apego exagerado aos próprios conceitos (Jung, 1985). Insistia em defender a prioridade dos fatos observados em relação às teorias, buscando primeiramente circunscrever e descrever os fenômenos psíquicos tais como eles se apresentam, sem a preocupação de encaixá-los numa teoria. O autor definia-se um empirista, um prático, 
permanecendo no nível fenomenológico, o que podemos perceber quando ele afirma: "Aos meus olhos, cada novo caso quase que consiste em uma nova teoria. (...) O que me perturba não são as teorias e sim um grande número de fatos" (Jung, 1985, p.32). Assim, para levarmos adiante nosso estudo, é preciso compreendermos como Jung entendia o psiquismo do ser humano, ainda que em linhas gerais.

Segundo o Jung (1985), em um primeiro plano, lida-se com a consciência, fenômeno observável ao qual se acessa diretamente. Dessa forma, não há nada consciente que antes não se tenha apresentado ao sujeito, ou seja, um conteúdo só é considerado consciente porque está em relação com um fator complexo denominado "eu", ou simplesmente, ego (Jung, 1985). Eis o critério para que algo seja considerado consciente.

Jung (1985) explica o "eu" como sendo um complexo de fatos psíquicos, inicialmente formado por uma percepção geral de nosso corpo e existência e, a seguir, pelos nossos registros de memória. Pode ser compreendido como o centro do campo da consciência, embora não seja equivalente à psique total.

A consciência é um campo restrito de visão momentânea. É característica do eu a seletividade, "certa estreiteza", apreendendo poucos dados em um determinado momento e definindo, assim, as limitações do sujeito. A organização percebida é resultado de uma sucessão de momentos conscientes que dá a impressão de continuidade e de identidade, pois também é graças ao "eu" que é possível sentir ser quem se é dia após dia (Jung, 1982).

O complexo do eu atua com uma força de atração poderosa, capaz de atrair conteúdos de outros campos que não sejam a consciência. Fornece um sentido de direção e consistência para a consciência, ainda que frágil. Dessa forma, 0 "eu" é sujeito de todos os esforços de adaptação do indivíduo. Essa função adaptativa é central para a compreensão do complexo do eu, bem como da consciência em Jung.

No âmbito da psicopatologia, então, é que tal função mostra claramente sua importância. Sobre isso, diz Jung (1985): "(...) enquanto esse homem puder explicar-se e eu sentir que podemos manter contacto, afirmarei que ele não está louco". Nesse sentido, quando constatamos um colapso dessa função adaptativa, é que se pode pensar em loucura, concepção extremamente relativa, como diz Jung (1985). Adiante a essa questão será abordada de modo mais detalhado, mas, por enquanto, ressalta-se a importância da função adaptativa, visto que até 
que ponto há uma diferenciação entre "normal" e "patológico" para a psicologia analítica.

Ao retomar o conceito de consciência, Jung (1985) fala, então, de uma "consciência do eu", reforçando, assim, o fato de que a consciência não equivale a toda a psique, e o "eu" também não dá conta da consciência como um todo:

Teoricamente, é impossível dizer até onde vão os limites do campo da consciência, porque este pode estender-se de modo indeterminado. Empiricamente, porém, ele alcança sempre o seu limite todas as vezes que toca o âmbito do desconhecido. (Jung, 1982, p.1)

O "desconhecido" é tudo aquilo que não possui relação com o "eu" (Jung, 1982), em outras palavras, é tudo que foi ignorado, não selecionado pela consciência. A esse respeito, Jung (1982) diz ser possível identificar dois grupos: o desconhecido do meio ambiente (fatores externos) e o desconhecido do mundo interior, ou seja, o inconsciente.

Este é referido por Jung (1986) como a soma dos processos que não são percebidos por não possuírem intensidade suficiente para ultrapassar o limiar que divide o que está consciente do que está inconsciente. Assim, um conteúdo inconsciente pode estar temporariamente subliminar, sendo reproduzível voluntariamente; pode não ser reproduzível segundo nossa vontade, mas irromper espontaneamente na consciência; e ainda pode ser totalmente incapaz de se tornar consciente, entrando nesse critério tudo aquilo que jamais irrompeu na consciência (Jung, 1982).

Como já foi citado, lida-se com a consciência em um primeiro plano, ou seja, de modo direto. Entretanto, a psique inconsciente não pode ser diretamente explorada por estar a um nível desconhecido, inacessível, sendo o ser humano capaz de lidar apenas com seus produtos conscientes, em um segundo plano (Jung, 1985).

Por conta disso, é desconhecido tudo a respeito do inconsciente em si: "Não se pode dizer coisa alguma a respeito daquilo sobre o qual nada se sabe. [...] Há apenas provas indiretas sobre a existência de uma esfera de ordem subliminar" (Jung, 1985, p.4). Para Jung, entretanto, é fato que "algo atua" quando nossa consciência falha, o que percebemos através de produtos de elementos inconscientes que atingem o campo consciente. Didaticamente serão abordadas duas espécies de produtos observados por Jung, entretanto, sem nos alongarmos em demasia nessas definições. 
Dentre tais produtos, existe uma espécie de material reconhecível, de origem pessoal. São aquisições do indivíduo que têm papel de completar sua personalidade. Há também conteúdos esquecidos ou reprimidos, além dos dados criativos, os quais podem se tornar conscientes, quando necessários. A esse grupo de elementos pessoais e que compõem a personalidade individual, Jung (1982) denominou inconsciente pessoal. Como exemplos de tais elementos, existem as idéias, percepções, traços de acontecimentos, representações penosas de serem lembradas ou carregadas de forte potencial afetivo, incompatíveis com a atitude consciente.

O outro grupo de dados observados por Jung tem sua origem desconhecida, ou pelo menos, com certeza, não são aquisições pessoais. É como se pertencessem à humanidade em geral, e não a uma psique individual. Representam uma base da psique em geral, universalmente presente e sempre idêntica a si mesma: "A mente do homem é pré-figurada pela evolução" (Jung, 1982). São fatores próprios do humano, sendo, pois, de natureza coletiva, impessoal. A estes, Jung denominou de inconsciente coletivo, obviamente, como uma hipótese resultante da espécie de material colhido ao longo da experiência clínica.

O inconsciente, dessa forma, jamais se acha em repouso, sempre agrupando e reagrupando conteúdos, sendo tal atividade, em geral, coordenada com a consciência, mas podendo se tornar completamente autônoma em certos casos (Jung, 1986). Tarefa fundamental do inconsciente nos indivíduos é o estabelecimento da compensação e o equilíbrio, no qual todas as tendências extremistas da consciência mostram-se atenuadas e suavizadas pelo impulso contrário inconsciente. Partes essenciais do inconsciente são os chamados erros compensatórios, os quais são caracterizados por compensar virtudes conscientes (Jung, 1986). Em oposição, as virtudes do inconsciente compensam certos defeitos conscientes. Jung (1986) aponta que os sonhos, por exemplo, revelam bastante sobre as ações compensatórias.

Ao afirmar que as intuições em pessoas normais não resultam de combinações lógicas do consciente, Jung (1986) as compara com as alucinações e ideias delirantes dos doentes mentais, pois estas últimas também não surgem de processos conscientes, mas sim, através de manifestações do inconsciente. Jung (1986) afirma que as alucinações e as ideias delirantes surgem uma vez que seus conteúdos inconscientes conseguem ultrapassar o limiar da consciência, 
e dessa maneira, manifestam-se nas ideias, pensamentos ou ações do indivíduo. Com isso, a atividade inconsciente aparece com maior claridade nos distúrbios de natureza psicogênica, tais como histeria e neurose obsessiva.

Segundo o autor (Jung, 1986), o "equilíbrio mental" não se mostra apenas como uma figura de linguagem, mas define, de certa forma, a relação de equilíbrio entre o conteúdo consciente e o inconsciente. Em pessoas anormais, apresenta-se bastante característica a recusa em aceitar a influência compensatória do inconsciente e essa irrupção atípica da atividade reguladora do inconsciente para com a consciência altera o ajustamento da pessoa ao meio em que vive. Assim, para Jung (1986), o sujeito tenta se defender contra seu próprio inconsciente, lutando contrariamente às influências compensatórias. Um estado de excitação que desencadeia uma grande desarmonia entre as tendências inconscientes e conscientes apresenta-se como o resultado desse duelo. Esclarece, ainda, que, quando o inconsciente começa a se sobrepor bruscamente à consciência, o sujeito encaminha-se para a doença. Esse conflito interno é marcado por incompreensíveis pensamentos, humores estranhos e alucinações.

Quando investigamos a história de vida de uma pessoa em que isto aconteceu, descobrimos com frequência que ela já vivia num estado peculiar de isolamento, fechada com maior ou menor intensidade para o mundo real. Esse estado de isolamento pode ser atribuído a certas singularidades inatas ou adquiridas na infância, as quais sempre se manifestam ao longo da vida. (Jung, 1986, p. 190)

De acordo com Jung (1986), o início de um processo de cura deveria começar quando impulsos corretivos ou compensações se manifestam na consciência. No entanto, o próprio autor diz que isso não acontece, uma vez que a consciência não se encontra capaz de aceitar esses impulsos corretivos oriundos do inconsciente (Jung, 1986). Devido a isso, essas influências compensatórias conseguem apenas irromper na consciência de maneira curiosa ao lutarem contra as resistências existentes, apresentando-se de forma bastante distorcida para o paciente, manifestando-se, assim, somente através da heterogênea linguagem do inconsciente.

A função do inconsciente nos distúrbios mentais, portanto, caracteriza-se pela compensação do conteúdo da consciência e essa função se evidencia quando tendências inconscientes se manifestam na consciência (Jung, 1986). Contudo, estas tendências conseguem se adaptar aos objetivos unilaterais da 
consciência e, consequentemente, brotando apenas de maneira inaceitável e distorcida (Jung, 1986).

Dentro dessa dinâmica, um aspecto importante apontado por Jung (1985) em sua teoria é o conceito de complexo, sendo este desenvolvido a partir de experiências que ele realizava com alguns de seus pacientes. Tais experiências ou testes de associação de palavras, segundo ele, tratam-se de um método de análise do inconsciente e consistem, basicamente, na emissão de uma lista de palavras-estímulo a uma pessoa, a qual responde com outra palavra após ouvir a palavra estímulo (Silveira, 1981).

Jung verificou que nessas respostas ocorriam, frequentemente, certos distúrbios. Essas reações aconteciam de várias maneiras como, por exemplo, a memória falhava, a pessoa respondia com expressão facial, movimentava as mãos ou gaguejava na hora de responder (Silveira, 1981). Segundo Jung, esse desconforto ou perturbação diante da palavra estímulo ocorria porque esta palavra atingia um complexo, o qual se trata de "[...] uma conglomeração de sentimentos estranhos ou dolorosos, normalmente inacessíveis ao contato exterior" (Jung, 1985, p.44).

Jung nos diz que os distúrbios de reação causados pelos complexos não ocorrem sob o domínio da vontade. Segundo ele, "Um complexo é um aglomerado de associações, espécie de quadro de natureza psicológica mais ou menos complicada, às vezes de caráter traumático, outras, apenas doloroso e altamente acentuado" (Jung, 1985, p.66). O complexo possui uma espécie de energia própria que lhe confere a tendência de formar uma pequena personalidade, ou seja, é um tônus que envolve certas reações fisiológicas, podendo perturbar, por exemplo, o batimento cardíaco. Assim, o complexo é relativamente autônomo, afirmando Jung que "[...] Tudo isso se explica pelo fato de a chamada unidade da consciência ser mera ilusão" (Jung, 1985, p.67).

Segundo a teoria junguiana a dissociação da personalidade ocorre, basicamente, devido à existência de complexos, e ter complexo é algo próprio do ser humano, ou seja, é normal, mas a incompatibilidade entre esses complexos e a consciência, dependendo do grau, pode estar na gênese de condições neuróticas e esquizofrênicas: "Os complexos divididos, por serem inconscientes, encontram meios indiretos de expressão, ou seja, através de sintomas neuróticos" (Jung, 1985, p.156). Por outro lado, se a separação entre a parte consciente e o conteúdo dos complexos for extremamente acentuado, "Se a 
fissura atingir a estrutura orgânica, a dissociação será uma psicose, uma condição esquizofrênica [...]" (Jung, 1985, p.156).

\section{METODOLOGIA}

Inicialmente, a equipe dividiu-se em dois grupos para a realização das visitas a um Hospital Psiquiátrico no estado do Ceará. Um aspecto positivo dessa divisão diz respeito à possibilidade de vivenciar momentos variados com a mesma pessoa, em um contexto diverso (no que se refere ao dia, ao momento, ao estado da paciente, entre outros), dessa forma, atentou-se para diferentes detalhes.

As visitas ocorreram nos dias 21 e 29 de junho de 2006, ambas ao pavilhão de internamento do hospital e durante o horário permitido para visitas à instituição, sendo uma realizada no turno da tarde e outra no turno da manhã.

A escolha da paciente para a realização do estudo ocorreu durante a primeira visita, admitindo-se como critério de escolha o fato da própria paciente iniciar o contato com o grupo. Por conta de mais de uma paciente ter se dirigido ao grupo, conversamos com duas em particular, mas, por questões metodológicas, decidimos por estudar um único caso. Preferimos não adotar uma investigação com base em entrevista formal, mas sim através de um diálogo que tinha como ponto de partida saber como se deu a chegada da paciente ao hospital.

Após o diálogo, foi realizada a leitura do prontuário da paciente. Realizamos as atividades nessa sequência, pois, na ocasião, pretendemos ter um contato inicial sem qualquer informação prévia sobre a paciente e, principalmente, com nossos olhares livres de um pensamento do tipo mosográfico, para em seguida avaliarmos os pontos de (dez) encontro entre o que obtemos através do diálogo e através do documento em questão.

No que se refere à segunda visita, o primeiro grupo informou para o segundo grupo o nome da paciente contatada, H., 25 anos, a fim de que tentassem um novo diálogo com a mesma e buscassem novas informações, impressões ou mesmo aspectos semelhantes aos já obtidos.

Finalizadas as etapas relacionada ao campo, a equipe voltou-se para a análise do diagnóstico psiquiátrico, relacionando-o com o diagnóstico psicológico, e para a formulação daquilo que acreditamos se aproximar de uma análise sob o enfoque da psicologia analítica. 


\section{O CASO}

Relato da paciente $H$.

Durante a primeira visita, $H$. veio ao encontro da equipe demostrando interesse em conversar. Já na segunta visita, a paciente disse que não estava com vontade de conversar e se afastou por estar chateada porque o médico não a tinha liberado para passar o fim de semana em casa. Porém, na medida em que a equipe iniciou a conversar com outras pessoas, ela se aproximou e disse que em vez de falar gostaria de cantar. Cantou duas músicas evangélicas e, em seguida, a equipe conseguiu dialogar, embora ela ainda não quisesse falar muito sobre determinados assuntos.

Fora esta especificidade, o discurso de $\mathrm{H}$. foi bastante similar nas duas ocasiões, com a predominância de um discurso religioso (evangélico), supervalorizando Jesus e seus ensinamentos.

Afirmou estar ali porque tinha "passado mal" e o pai, em vez de levá-la para um posto de saúde, como ela havia requisitado, a internou no HSMM porque não gostava dela. Relatou que no dia 13 de junho estava "passando mal por dentro", com "fraqueza no corpo" devido a um "problema espiritual", a uma "coisa do inimigo". Porém, em seguida, afirmou que "o inimigo está derrotado em nome de Jesus". Não quis falar o motivo da fraqueza, disse que Jesus não queria que falasse sobre isso. "Não quero lembrar, o que passou, passou".

Quando chegou ao hospital com o pai, disse que ficou cantando músicas de louvor e lendo a Bíblia na entrada da instituição. "Meu pai me trouxe pra cá só porque eu tava chorando, pensava que eu tava doida". Afirmou estar realmente doente nas outras vezes em que foi internada, mas dessa vez não tinha problema algum, pois Jesus a tinha "livrado". "Jesus me curou, ele disse que eu tô curada". Questionada sobre como era esse "estar doente" nas outras vezes, respondeu não querer falar muito e se limitou a dizer que tinha depressão, ficava triste, não dormia à noite e não comia.

Insistimos mais algumas vezes em perguntar sobre o que ela sentia quando estava com "fraqueza", ao que respondeu dizendo que via vultos, mas "que Jesus já derrubou por terra", e que ouvia vozes chamando por ela e assutando, mas que "Jesus já tirou". "Quero lembrar disso não. Era coisa ruim". Disse que tais vozes não eram de Jesus, pois este ela escutava "em silêncio". 
Quanto ao pai, disse que este pensa que ela é "doida". Demonstra muito rancor por ele a ter internado. "Ele vai pagar um preço por ter me trazido pra cá". Informou-nos, também, que tinha dois irmãos e cinco irmãs.

Ao perguntarmos a respeito de sua mãe, não quis falar muito, dizendo apenas que não a via há muito tempo, pois seus pais eram separados. Começou a falar sobre seu filho, de três anos, descrevendo-o fisicamente e dizendo que sentia muita saudade dele. Não quis falar sobre o pai da criança ("Pra que falar de coisa triste?"), dizendo em seguida que ele era casado com outra.

Durante a primeira visita, H. portava uma sacola de plástico, onde guardava uma Bíblia (sua "arma de guerra") e duas garrafas plásticas com água. Segundo ela, a água, que havia retirado da torneira, era "benta por Jesus". Em todos esses objetos, bem como em sua roupa e em partes do seu corpo, havia escrito à caneta a palavra "Jesus" ou "Deus". "Não largo Jesus por nada, fico direto agarrada com essa sacola", disse H. Mostrou que dentro da Bíblia havia um prendedor de cabelo, o qual pertencia a outra pessoa, e disse que queria devolver o objeto pois só queria o que fosse dela.

Afirmou ter trabalhado como doméstica. Queixou-se da dona da residência em que trablahava, pois esta "reclamava de tudo" e não a deixava sair "para fazer as coisas de Deus", por isso terminou por abandonar o emprego.

Quanto à medicação, disse por várias vezes que não precisa tomar, pois Jesus a tinha curado. Por outro lado, em outro momento, afirmou que Jesus queria que ela tomasse os remédios "pra cabeça" para vê-la melhor, por isso aceitava a medicação receitada no hospital. Além disso, ainda chegou a nos perguntar se achávamos que ela precisava tomar os remédios.

Durante a segunda visita, falou que gostava de assistir os jogos do Brasil durante a Copa do Mundo e que, inclusive, tinha acertado o placar do jogo Brasil versus Japão, enfatizando que ela mesma havia "determinado" que o Brasil iria ganhar.

A exemplo da primeira vez, falou muito a respeito de Jesus e sobre a Igreja que frequentava (Igreja Evangélica do amor de Deus, na Maraponga). A religiosidade se fazia muito forte e recorrente em seu discurso. "Todo mundo passa mal, né? Não tô doente, só preciso ir pra igreja", disse H. Cantou algumas músicas evangélicas para a equipe e disse que precisava sair para ir à igreja cantar no coral do qual participava. 
Sobre o hospital, disse que não gostava do lugar, pois só tinha "doido" e ela não era doida. "Tenho pena do povo daqui porque tão doente e abobado por causa do remédio", disse-nos, afirmando que não ficava do mesmo jeito porque se "agarrava a Jesus". Relatou sentir falta de "fazer algo", que na terapia ocupacional só havia pintura e desenho e "isso é coisa de criança".

História clínica

$\mathrm{Na}$ tentativa de analisar a história clínica da paciente, fizemos uso de seu prontuário, cedido pela equipe de enfermagem. Durante nossa leitura do mesmo, procuramos levantar o motivo da internação da paciente, o diagnóstico psiquiátrico do caso, bem como observar os sintomas e possíveis alterações de suas funções psicológicas.

Com o intuito de retratar o formato como se estrutura o prontuário, tentaremos adaptar o modelo do mesmo ao nosso trabalho, expondo, assim, a transcrição exata do documento em questão. Basicamente, o prontuário é formado por alguns documentos institucionais juntamente com o relatório diário sobre o comportamento da paciente, cada qual feito por um profissional diferente, em geral, assistentes sociais e, raramente, um médico psiquiatra.

Ao final do trabalho, segue em anexo o quadro psicopatológico com base no CID 10, no qual $H$. foi enquadrada por um psiquiatra comportamental, funcionário do hospital, para que possamos ter acesso a uma leitura das especificidades do transtorno em questão.

\section{Prontuário}

Nome da paciente: H., 25 anos.

Data da internação: 13/06/2006

Diagnóstico psiquiátrico de acordo com o Cid 10: F31- Transtorno afetivo bipolar.

Condição que justifica a internação: Risco para si.

A paciente foi internada involuntariamente.

Justificativa da involuntariedade: Fala da igreja cristã.

Principais sintomas: Logorréica, fuga do lar, pouco apetite, agressividade com a família; delírio de grandeza.

Durante as crises: Apresenta impulsos agressivos, insônia, agitação psicomotora, alucinação, fuga da família.

Dia 13: Esteve internada outras vezes, tem oito irmãs, há treze anos q têm os sintomas, tem uma irmã com problemas semelhantes: impulsos agressivos, 
insônia, alucinações, agitação psicomotora, empreende fuga do lar; em casa não colabora e não aceita medicação regularmente, pais separados há aproximadamente cinco anos, sem benefício junto ao INSS, é mantida pelo pai com renda de duzentos e oitenta reais, mora na Maraponga, possui filho de três anos, separada, estudou até a $4^{a}$ série. Momento de crise: confusa, exaltada, agressiva, aceitou medicação.

Dia 14: isolada, idéia de devoção, pouco comunicativa, delírios místicos (primeiro dia de medicação).

Dia 15: ansiosa, confusa, aceita medicação.

Dia 17: ansiosa, inquieta, momentos delirantes, crise de choro (medicada de urgência).

Dia 20: afirma que estudou até a $8^{a}$ série, se diz desempregada, quem lhe sustenta é a irmã, não é o pai porque ele não quer ter trabalho com ela, afirma ter outros internamentos (informações obtidas por uma assistente social através de uma conversa com a paciente). Momento de crise: alucinou, ouve vozes, vê vultos, anda muito, "não sou doente, é só fraqueza", insiste em pedir licença no final de semana pra realizar obras de Deus, fala muito da igreja, escreve textos de referência a Deus e Jesus; fez uma lista com pedidos de objetos e frutos para ser repassada à irmã, e logo em seguida, pediu de volta, dizendo que, quando sair compra; "meu pai como sempre vai rir de mim".

Medicação: Revectina (indicado para escabiose e piolho), Benzato de Benzila (escabiose), Haldol (antipsicótico), Depakene (estabilizador de humor), Fenergam (sedativo), Melleril $100 \mathrm{mg} 1 \mathrm{cp}$ (anti-psicótico), Vulprami (estabilizador de humor).

Para maior esclarecimento, apresentamos a seguir a definição dos sintomas registrados no prontuário da paciente H.. Com base no Glossário de termos psiquiátricos clássicos (Martins, 2003), temos o seguinte.

Logorréia: Aumento exagerado do ritmo da fala. Trata-se de um fluxo incessante e incoercível de palavras emitidas sem coesão lógica, que se acompanha da aceleração do ritmo psíquico e da elevação do estado de ânimo. É comum em todas as excitações psicomotoras, principalmente nos estado maníacos e hipomaníacos e na embriaguez alcoólica.

Fuga: Estado em que se observa um impulso motor irresistível de escapar (no caso, do lar), fugir, vaguear, com a consciência obnubilada.

Hiporexia: diminuição do apetite. 
Delírio: São juízos infundados que ocorrem ao indivíduo, que os vivencia como verdades incontestáveis e retira delas consequências. São desordens primárias do juízo, isto é, que não se podem deduzir de outras experiências, nem racionais nem emocionais. Por isso, os paciente são capazes de discorrer com uma lógica impecável que é, portanto, consonante com a falsidade que lhe serve de ponto de partida. A premissa é falsa, mas o raciocínio a partir desse princípio falso é perfeitamente coerente. São reconhecidos alguns sinais exteriores do delírio segundo Jaspers: a convicção extraordinária com a qual são mantidos tais juízos, com uma certeza subjetiva notável; a impermeabilidade a experiências e refutações lógicas; a inverosimilhança do conteúdo; tem um caráter central, tornando-se o eixo da vida, das preocupações do indivíduo.

Agitação psicomotora: estado ou paroxismo motor intenso. Pode ser dirigida (no caso, para a família), associada com episódio agressivo violento, ou desorganizada.

\section{PSICOPATOLOGIA E ANÁLISE DO CASO}

O materialismo dominante no final do século $X X$ muito influenciou a teoria psiquiátrica, considerando as doenças mentais como resultantes de alterações de origem cerebrais e apontando os casos de neurose como "intoxicações no metabolismo ou distúrbios das secreções internas" (Jung, 1986). Janet, com as experiências da psicopatologia francesa, juntamente com o auxílio de Forel e Freud (Alemanha), contribuiu para a ruptura com as idéias referentes às causas orgânicas das neuroses. Atualmente leva-se em consideração, indubitavelmente, o fundamento psicogênico das neuroses, embora, a questão da psicogênese relativa a outras doenças mentais seja questionável e não claramente observada.

Psicogênese significa "causa essencial de uma neurose, ou a condição em que ela irrompe, é de natureza psíquica. Pode ser um choque psíquico, um conflito desgastante, uma adaptação psíquica errônea ou uma ilusão fatal" (Jung, 1986, p.213).

Jung denomina para os casos de psicose a esquizofrenia e a paranóia. A esquizofrenia constitui o que o público leigo a denomina como "loucos". Seria a constituição do que é nomeado de doença mental, apresentando grande número de casos que são atendidos nas clínicas. A esquizofrenia possui causa e fim psíquicos, tal qual ocorre na vida mental de uma pessoa dita normal. A diferença marcante, porém, é que para a pessoa normal, o eu é o próprio sujeito da 
experiência, enquanto no esquizofrênico, o eu sofre uma fragmentação em que passa a coexistir uma variedade de sujeitos, de funcionamento autônomo (Jung, 1986).

A paranóia (Jung, 1986), classicamente considerada mania de perseguição, constitui o caso mais simplificado de fragmentação da personalidade. Ocorre uma espécie da duplicação da personalidade, mas em que os "eus" conseguem se relacionar entre si, mantendo uma certa identidade entre eles.

Jung (1986) destaca a importância da psicogênese como fator fundante para os distúrbios mentais, considerando as alterações cerebrais que , porventura existam, como fenômenos de grau secundário, embora as questões relativas à base orgânica continuem em profunda discussão.

Ao falar da psicogênese da esquizofrenia, que será utilizada por Jung, para ilustrar de forma geral o quadro da psicose, faz-se necessário falar do conceito proposto por Pierre Janet de "abaissement du niveau mental", o que significaria uma redução do nível mental consciente. Tomando-se a força de vontade como a que dirige a vida psíquica, o conceito de "abaissement" explica "o estado psíquico em que uma seqüência de pensamentos não é capaz de alcançar um desencadeamento lógico, ou é interrompida por conteúdos estranhos que não foram suficientemente inibidos" (Jung, 1986, p.220). Esse conceito referido por Janet corresponderia aos sintomas caracterizados como primários, fundalmentalmente psíquicos, como dito por Bleuler.

A partir dos testes de associação (como já dito anteriormente) aplicados aos neuróticos, pode-se observar o quanto os processos normais de associação se encontram perturbados por conteúdos complexos, desconhecidos, que invadem a consciência, o que caracteriza a reduçaõ do nível mental. A dissociação pode ser tão forte ao ponto de serem criadas personalidades secundárias, cada uma delas dotada de autonomia, de consciência própria. Deve-se destacar, portanto, a diferença existente entre a neurose e a psicose. No caso da neurose há uma preservação da "unidade potencial da personalidade" (Jung, 1986, p.220). Já na esquizofrenia, "a ligação entre o eu e os demais complexos se encontra, às vezes mais, às vezes menos, inteiramente rompida. A cisão não é relativa e sim absoluta" (Jung, 1986, p.221). Na neurose, os complexos se comportam de forma relativamente autônoma, enquanto na esquizofrenia, os complexos se separam tais quais fragmentos independentes e autônomos, não se reitegrando à unidade psíquica, ou se interligando de forma desconexa e inesperada. A 
dissociação é, portanto, muito mais grave do que a ocorrida na neurose, constituindo, geralmente, um quadro irreversível.

A totalidade psíquica, na esquizofrenia, através do "abaissement", se esfacela, como um espelho partido, em que cada complexo constituirá uma personalidade individual. O complexo de eu se despotencializa, passando a ser apenas um dos vários complexos a existirem simultaneamente.

As figuras cindidas possuem nomes e características banais, grotescas, caricaturais, e, em muitos aspectos, contestáveis. Além, disso, não colaboram com a consciência do paciente. [...] intrometem-se e perturbam o tempo inteiro, atormentando o eu de inúmeras maneiras. [...] Trata-se visivelmente de um caso de visões, vozes e tipos desconexos, todos de natureza violenta, estranha e incompreensível [...] (Jung, 1986, p.221).

Na redução do nível mental, a autonomia dos fragmentos cindidos fogem ao controle do eu, restringindo sua responsabilidade para uma adequada atuação. O limiar da consciência reduz-se ao ponto de permitir que conteúdos inconscientes invadam, de forma autônoma, a esfera consciente. Com isso, ocorrem reações de caráter emocional inadequadas, provocando idéias incompletas da realidade.

Quanto ao caso clínico de H., percebe-se que a exacerbação do discurso religioso e o fato de Jesus "falar" e pedir para que ela tome o remédio adequadamente, possibilita que haja uma certa adaptação, mesmo que muito fragilizada, nos momentos de não surto. Para ela, Jesus a curou e a livrou de todo o passado. "O inimigo está derrotado em nome de Jesus Cristo" e isto a permite aceitar a medicação, embora não admita estar doente. Este fato a assegura de não estar freqüentemente em situação de surto. A repressão de conteúdos, porém a deixa na iminência de sua ocorrência, o que pode ser verificado pela alteração profunda do humor quando impedida pelos médicos de retornar ao lar. Neste momento, assim como quando a indagamos sobre determinados aspectos de sua história de vida, como sua "fraqueza", sua mãe e o pai do seu filho, ela mostra-se profundamente afetada, ocorrendo, assim, uma invasão de conteúdos que não podem ser mais barrados conscientemente, tocando-se, portanto, nos complexos de tonalidade afetiva.

Pode-se observar uma constante alteração no discurso de H., embora haja uma certa coerência com o que foi relatado nas duas visitas realizadas pelo grupo e com o que consta no prontuário do hospital. Como foi dito em relação à psicose, a dissociação ocorre como a coexistência de diversos "eus" sem conexão 
entre si, cindindo o centro da personalidade do indivíduo. O discurso de $\mathrm{H}$. aparentava conter outros eus existindo concomitantemente, como se uma parte dela não fosse reconhecida como pertencente a sua personalidade central.

Vale ressaltar, que a terminologia empregada no prontuário do hospital Transtorno afetivo bipolar - não é utilizada por Jung. Em sua teoria, interessa-se por explicar o funcionamento psíquico da psicose. Considera o quão forte é a dissociação, como ocorre a cisão da personalidade do indivíduo empregando, assim, o termo esquizofrenia para representar os casos mais gerais relativos á psicose.

Com base no exposto, tentamos compreender aspectos do diagnóstico psiquiátrico de $\mathrm{H}$. tentando-se uma aproximação com o que seria uma análise psicológica. Primeiramente, devemos salientar que Jung, recusava-se a explicar o normal tomando por base o patológico. Não tratava diretamente de uma psicopatologia, mas sim de uma psicologia geral que levasse em consideração o material patológico (Jung, 1985). Dessa forma esforçou-se por remover sua psicologia do campo do estritamente patológico, por considerar a pessoa normal bem mais valiosa e interessante (Jung, 1999).

No contato com H., logo de início percebemos uma exacerbação da temática religiosa em seu discurso. Quando perguntamos sobre o motivo de sua internação, H. disse ter sentido uma "fraqueza". Quando tentávamos aprofundar essa questão, $\mathrm{H}$. dizia ouvir vozes e "ver coisas", sem dizer exatamente do que se tratavam esses fenômenos. Recorria sempre à fuga por meio do discurso "Não quero falar sobre isso $[. .$.$] Isso era coisa do inimigo [\ldots]$ Jesus me curou".

Nesse sentido, podemos fazer referência à concepção medieval da psicopatologia, caracterizada pela visão da loucura como uma possessão da pessoa pelo diabo. Sobre isso, Beauschesne (1989, p. 95) esclarece: "As formas de loucura que implicam geralmente o delírio, como a mania e a melancolia, podem resultar da ação direta do demônio, ou de ação imediata por maquinações de qualquer bruxa".

Dessa forma, acreditava-se que o demônio se alojava no corpo da pessoa, principalmente na cabeça, o que era definido como possessão, ou pensava-se, frequentemente, que o diabo perseguia a vítima, alterando suas percepções, emoções, sentimentos, visões, entre outras coisas (Beauschesne, 1989). Assim, podemos ver certa semelhança entre tal concepção e o discurso de H., uma vez que a paciente garante ouvir vozes do "inimigo" nos estados de crise, a qual 
afirma se tratarem de "momentos de fraqueza", dizendo ter sido Deus quem a salvou, portanto, curou.

A psicose, para Jung (1986), apresenta tanto conteúdos de caráter pessoal quanto de caráter coletivo, sendo, nesses últimos, verificados a enorme presença de símbolos coletivos. Partindo desse olhar, percebemos a recorrência (repetição), no discurso de H., da experiência religiosa. Sem perdermos de vista a singularidade da experiência de $\mathrm{H}$., podemos inferir que tais conteúdos místicos são de caráter coletivo. Essa temática, inclusive, é recorrente não só em H., mas em grande parte das mulheres em situação de internamento no pavilhão do Hospital.

A esse respeito, Jung (1986) diz: "De fato, o doente mental sempre gostou do privilégio de ser um possuído pelos espíritos ou perseguido por um demônio", pois seu estado psíquico é mesmo invadido por fisionomias e formas de pensamento autônomo. Podemos assim fazer referência às vezes em que $\mathrm{H}$. diz que Jesus falava com ela: "Eu escuto Jesus em silêncio", bem como sobre a ocasião em que disse ter visto Jesus: "Vi uma fumaça branca e senti uma coisa boa $[\ldots]$ era Jesus".

Sobre o ponto de vista do primitivo, é bem claro que o inconsciente se apoderou do eu, através de seus próprios impulsos. Sendo assim, não é o eu que enfraquece mas o inconsciente que se fortalece com a presença do demônio. O primitivo, portanto, não busca a causa do distúrbio mental num enfraquecimento primário da consciência mas no fortalecimento extraordinário do inconsciente. (Jung, 1986, p.228)

Ainda sobre a experiência religiosa, durante a conversa com $\mathrm{H}$., esta segurava em mãos uma sacola contendo duas garrafas plásticas e uma Bíblia: "Não largo Jesus por nada, fico direto agarrada com essa sacola". Disso podemos inferir que tais objetos serviam como uma forma simbólica de concretizar Jesus. Faz parte ainda de suas fantasias o fato de $\mathrm{H}$. dizer que a água (que ela tirou da torneira do pavilhão) de suas garrafas foi abençoada por Jesus. A ausência de um intermediário (como um padre, um pastor, alguma figura representativa) para concretizar tal benção fez-nos pensar em tal afirmativa como algo não muito comum.

Jung (1985) aponta que "estar louco é uma concepção extremamente relativa". Assim, pensamos que, em outro contexto, tais comportamentos de $\mathrm{H}$. poderiam ser aceitos como algo natural, sendo ela considerada apenas alguém muito religiosa. Dessa forma, ainda que exista um funcionamento psíquico "anormal", provém da sociedade a designação de quem é ou não louco: "Usamos 
restrições e convenções sociais a fim de reconhecermos desequilíbrios mentais" (Jung, 1985).

\section{CONSIDERAÇÕES FINAIS}

No que se refere à questão dos diagnósticos psiquiátrico e psicológico, Jung considerava que a anamnese psiquiátrica se caracteriza por uma visão médica unilateral a respeito do problema de um paciente por não possuir o conhecimento psicológico necessário à análise do caso. "A maioria dos sintomas é determinada psicologicamente sob a influência de fatores psíquicos ou relacionados a eles" (Jung, 1985). Assim, considerava a classificação nosográfica insuficiente por negligenciar as especificidades de cada caso.

Ressaltava também (Jung, 1985) que o próprio diagnóstico psicológico não resolve em definitivo o conflito do sujeito, apenas proporciona certa orientação, não sendo capaz de compreender completamente o que afeta o indivíduo, ou seja, é eficiente na descrição, porém insuficiente na terapêutica. Desta forma, para Jung (1999), diagnosticar não significa declarar alguém patológico, mas significa conhecer as características de um determinado estado psicológico.

\footnotetext{
Análise não é apenas "diagnóstico", mas antes é compreensão e suporte moral no esforço e experiência honestos que chamamos "vida". Nunca podemos saber melhor ou de antemão o que afeta o indivíduo. Só podemos ajudar a pessoa a se compreender a si mesma, a tomar coragem para a tentativa e o desafio. (Jung, 1999, p. 62-63)
}

Desse modo, Jung (1985) defendia que o terapeuta deve se esforçar para não fechar sua compreensão em torno do que sabe, até então, a respeito do paciente, mas lhe dar uma chance em aberto para que este apresente seu material com maior liberdade. Jung (1985) dava importância ao relato do paciente por considerar a continuidade inerente à estrutura psíquica do indivíduo.

Ao final dessa análise, compreendemos ser muito complicado inferir sobre o quadro clínico de uma pessoa. Antes de tudo, porque, partindo de um constructo teórico complexo como a psicologia analítica, seria fundamental uma apropriação teórica de maior profundidade por parte da equipe. Além disso, vemos como extremamente importante um período que possibilitasse maior aproximação com a paciente em questão.

Refletindo sobre possibilidades de tratamento que fossem além do uso de medicação, pensamos em uma terapêutica focalizada no relato e na história de vida do paciente, bem como um método de análise através dos sonhos, via eficaz 
para o acesso dos conteúdos inconscientes. Segundo Jung (2006), "O ponto decisivo é a questão da 'história' do doente, pois revela o fundo humano, o sofrimento humano e somente aí pode intervir a terapia do médico".

Se tomarmos por base os estudos de caso realizados pelo próprio Jung, veremos uma grande disparidade entre a análise por ele desenvolvida, caracterizada por um processo extenso e repleto de conexões com outros estudos, e o presente trabalho. Este, na verdade, trata-se de um possível caminho na formulação do que acreditamos se aproximar de uma análise sob o enfoque da psicologia analítica.

O fato decisivo é que, enquanto ser humano, encontro-me diante de um outro ser humano. A análise é um diálogo que tem necessidade de dois interlocutores. O analista e o doente se encontram face a face, olhos nos olhos. O médico tem alguma coisa a dizer, mas o doente também (Jung, 2006).

\section{REFERÊNCIAS}

Beauchesne, H. (1989) As origens da psicopatologia. In: H. História da psicopatologia. São Paulo: Martins Fontes.

Jung, C. G. (1982). Áion: Estudos sobre o simbolismo do si-mesmo. Petrópolis: Vozes. v.IX/2.

Jung, C. G. (1984). O eu e o inconsciente. 4.ed.Petrópolis: Vozes. v.VII/2.

Jung, C. G. (1985). Fundamentos de psicologia analítica. 3.ed. Petrópolis: Vozes. V.XVIII/1.

Jung, C. G. (1985). A prática da psicoterapia. 2.ed. Petrópolis: Vozes. v.XVI/1.

Jung, C. G. (1986). Psicogênese das doenças mentais. Petrópolis: Vozes. v.III.

Jung, C. G. (1994). Estudos psiquiátricos. Petrópolis: Vozes. v.I.

Jung, C. G. (1999). Cartas. Tradução Edgar Orth. Petropolis: Vozes.

Jung, C. G. (2006). Memórias, sonhos e reflexões. 1.ed. especial. Rio de Janeiro: Nova Fronteira.

Martins, F. (2003). Psicopatologia II - semiologia clínica: Investigação teóricoclínica das síndromes psicopatológicas clássicas. Brasília: ABRAFIPP/Laboratório de Psicanálise e Psicopatologia, UnB.

Silveira, N. (1981). Jung: Vida e obra. 12.ed. Rio de Janeiro: Paz e Terra. 
Contato: bianapsq@hotmail.com, monica.tass@gmail.com, narathais.psi@gmail.com, sabrinaleitecardoso@yahoo.com.br

Recebido em: 11/08/2013

Revisado em: $14 / 12 / 2013$

Aceito em: 06/02/2014 